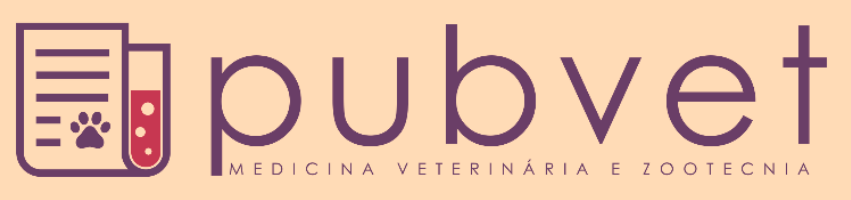

https://doi.org/10.31533/pubvet.v14n5a571.1-8

\title{
Estudos científicos sobre gatos ferais no Brasil
}

\author{
Gabriel Jorge Chula Pereira ${ }^{1 *}$, Helba Helena Santos-Prezoto ${ }^{2} \bullet$, Anna Marcella Neves Dias ${ }^{30}$,

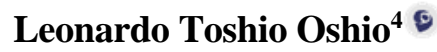

${ }^{I}$ Graduando de Medicina Veterinária pelo Centro Universitário Presidente Antônio Carlos -UNIPAC. Juiz de Fora-MG Brasil. ${ }^{2}$ Docente do curso de Medicina Veterinária do Centro Universitário Presidente Antônio Carlos-UNIPAC. Juiz de Fora-MG Brasil. ${ }^{3}$ Diretora do Centro Universitário Presidente Antônio Carlos-UNIPAC. Juiz de Fora-MG Brasil.

${ }^{4}$ Coordenador e docente do curso de Medicina Veterinária do Centro Universitário Presidente Antônio Carlos. Juiz de Fora-MG Brasil. *Autor para correspondência, E-mail: gabriel.chula@hotmail.com

Resumo. Os gatos convivem com os seres humanos há tempos e essa relação vem se estreitando a cada dia mais, no entanto muitos problemas comportamentais são resultados de falhas ao avaliar as reais necessidades de um gato e suas condições ambientais. Esses problemas são a principal causa de abandono, levando os animais desde as ruas até a eutanásia. Nos ambientes urbanos, a presença de animais ferais vem se tornando uma grande preocupação de saúde pública, pois dos gatos ferais, somente uma reduzida parcela é vacinada ou possui um tutor responsável. O presente estudo teve como objetivo analisar as publicações científicas e traçar um perfil dos estudos feitos no Brasil sobre o tema "gatos ferais". Os dados foram coletados a partir de levantamento de estudos científicos (artigos, livros, monografias, dissertações e teses) disponibilizados digitalmente em sites de busca e de pesquisa, sendo eles Google acadêmico, Scielo, PubVet, PubMed. Foram encontrados 58 estudos científicos publicados, entre 2002 a 2019, e desses, 28 estão relacionados à temática de doenças e zoonoses, 20 relacionados a predação e impacto ambiental e, 10 a comportamento animal. O início das publicações sobre o tema foi em 2002, tendo um pico em 2015, e a região sudeste do país foi onde se concentra o maior número de estudos. Conclui-se que estudos sobre o tema são carentes, sendo necessárias pesquisas que se aprofundem mais na avaliação do comportamento dos gatos ferais.

Palavras chave: Comportamento, Felinos, Impacto ambiental, Predação, Saúde

\section{Scientific studies on wild cats in Brazil}

Abstract. Cats have been living with humans for a long time and this relationship has been getting closer and closer, however many behavioral problems are the result of failures in assessing a cat's real needs and environmental conditions. These problems are the main cause of abandonment, taking animals from the streets to euthanasia. In urban environments, the presence of feral animals has become a major public health concern because of feral cats, only a small portion is vaccinated or has a responsible guardian. The present study aimed to analyze scientific publications and profile the studies done in Brazil on the theme of "feral cats". Data were collected from surveys of scientific studies (articles, books, monographs, dissertations and theses) made digitally available on search and research sites, being Google Academic, Scielo, PubVet, PubMed. We found 58 published scientific studies, from 2002 to 2019, of which 28 are related to diseases and zoonoses, 20 related to predation and environmental impact and 10 to animal behavior. Publications on the topic began in 2002, peaking in 2015, and the southeastern region of the country was where the largest number of studies is concentrated. It is concluded that studies on the subject are lacking, requiring further research to evaluate the behavior of feral cats.

Keywords: feral cats, predation, environmental impact, health, behavior 


\section{Estudios científicos sobre gatos salvajes en el Brasil}

Resumen. Los gatos han estado viviendo con humanos durante mucho tiempo, y esta relación se ha ido estrechando cada vez más, pero muchos problemas de comportamiento son el resultado de fallas en la evaluación de las necesidades reales y las condiciones ambientales de un gato. Estos problemas son la causa principal del abandono, llevando animales de las calles a la eutanasia. En entornos urbanos, la presencia de animales salvajes se ha convertido en un importante problema de salud pública debido a los gatos salvajes, solo una pequeña parte está vacunada o tiene un tutor responsable. El presente estudio tuvo como objetivo analizar las publicaciones científicas y perfilar los estudios realizados en Brasil sobre el tema de los "gatos salvajes". Se recopilaron datos de encuestas de estudios científicos (artículos, libros, monografías, disertaciones y tesis) disponibles digitalmente en sitios de búsqueda e investigación, a saber, Google Scholar, Scielo, PubVet, PubMed. Encontramos 58 estudios científicos publicados, de 2002 a 2019, y 28 de ellos están relacionados con el tema de las enfermedades y las zoonosis, 20 relacionados con la depredación y el impacto ambiental, y 10 con el comportamiento de los animales. Las publicaciones sobre el tema comenzaron en 2002, alcanzando su punto máximo en 2015, y la región sureste del país fue donde se concentra la mayor cantidad de estudios. Se concluye que faltan estudios sobre el tema y se necesita más investigación para evaluar el comportamiento de los gatos salvajes.

Palabras clave: Comportamiento, felinos, impacto ambiental, depredación, salud

\section{Introdução}

O gato doméstico (Felis catus) hoje está amplamente estabelecido e adaptado em território mundial, muito utilizado como controlador de pragas ao longo da história, por sua grande capacidade de predação. (Ferreira et al., 2012). Por esse motivo, se aproximou dos seres humanos e até hoje está presente no território urbano, se tornando parte das famílias do século XXI. Como é um animal muito prolífero, sua população cresceu desordenadamente nos últimos anos e o abandono se tornou frequente quando este se torna indesejável. A partir daí, perambulam pelo meio urbano e rural, causando sérios danos ao meio ambiente (Vilela \& Lamim-Guedes, 2014).

No meio urbano, a grande presença de gatos pode promover peculiar impacto sobre a população selvagem vizinha, além da atividade predatória, esses animais podem transmitir doenças sendo vetor de vários agentes etiológicos, disseminando patologias para várias espécies, incluindo humanos (Kerber, 2017). Mesmo em condições domiciliares, tendo ou não acesso ao meio externo, os gatos podem se tornar potenciais predadores oportunistas. Estudos sobre a interação dos animais domésticos e a fauna brasileira ainda são escassos. É preciso avaliar os reais impactos que esses predadores exóticos podem causar em território nacional, bem como avaliar possíveis ações voltadas a controlar ou até mesmo erradicar o problema em locais que já foi apresentado ou utilizando ferramentas para prevenção. (Ferreira, 2016).

Considerando a relevância do tema para melhor compreensão da interação dos gatos ferais com o ambiente urbano e com o homem, o presente estudo teve como objetivo realizar uma análise dos estudos científicos publicados sobre gatos ferais, no Brasil, através da temática abordada.

\section{Material e métodos}

Esta pesquisa foi um estudo de revisão bibliográfica e posterior análise (por meta-análise) de trabalhos pesquisados eletronicamente por meio de banco de dados como Google Acadêmico, Scientific Electronic Library Online (Scielo), PubVet, PubMed entre outros sites de pesquisa. Durante o levantamento foram obtidos artigos científicos, monografias dissertações, teses e livros, que tratavam do assunto. Sendo então selecionados trabalhos da literatura médica inglesa e portuguesa, publicados no período de 2002 a 2019. Para a busca foram utilizadas as seguintes palavras-chave: gato feral, comportamento, doença, impacto ambiental, predação. 
A partir da revisão, os trabalhos produzidos no Brasil foram classificados por ano de publicação e local onde o estudo foi realizado. Além disso, foram estabelecidos três grupos para classificação quanto a abordagem dos trabalhos: comportamento, saúde, impacto ambiental e predação. Os dados coletados referentes ao ano de publicação, as regiões brasileiras de estudos, classificação quanto abordagem, aos tipos de doenças enfocadas e a via de publicação, foram analisados de forma descritiva.

\section{Resultados e discussão}

Foram encontrados 58 estudos científicos publicados, entre 2002 a 2019, no Brasil com a temática gatos ferais. Desses, 28 (48,3\%) estão relacionados à temática de doenças e/ou zoonoses, 20 (34,5\%) estão relacionados ao comportamento de predação dos gatos ferais e ao impacto ambiental que eles podem causar, e $10(17,2 \%)$ tratam sobre o comportamento animal (Figura 1).

As publicações que relatam sobre a relação de gatos ferais no risco de transmissão de doenças e/ou zoonoses ocorreram a partir de 2004, onde se aborda doenças e possíveis transmissões à vida silvestre e demais animais domésticos em ambiente peri urbano. Quanto aos estudos classificados em doenças/zoonoses, $12(42,8 \%)$ se referiam diretamente a zoonoses, onde vale destacar a toxoplasmose $(n=5)$ e a leptospirose $(n=3)$. Trabalhos que relatam estudos epidemiológicos, estado de saúde e risco de transmissão de doenças foram $7(25,0 \%)$ e sobre doenças não zoonóticas como, por exemplo, o vírus da leucemia felina foram $9(32,2 \%)$ (Figura 2).
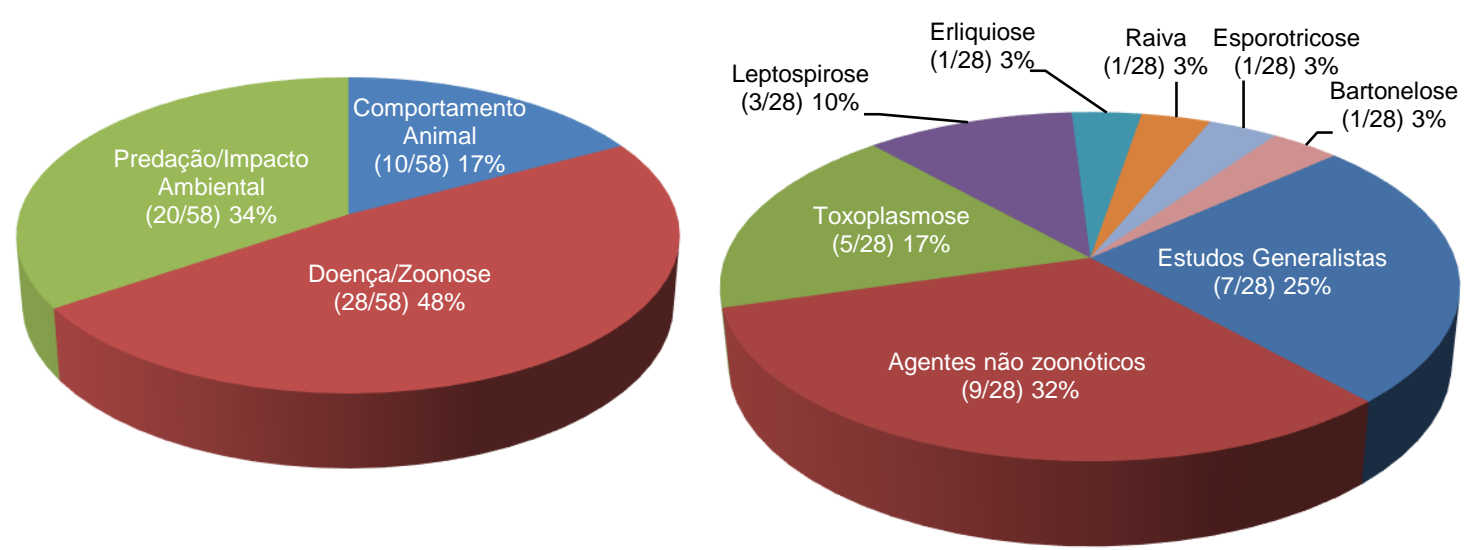

Figura 1. Categorização e distribuição dos estudos Figura 2. Divisão dos estudos científicos publicados sobre os temas científicos publicados sobre o tema Gatos Ferais, no Brasil no período de 2002 e 2019.

"Gatos Ferais" e "Doenças/Zoonoses", no Brasil no período de 2002 e 2019.

Apenas um único estudo abordou sobre doenças relevantes como Bartonelose, Esporotricose, Raiva e Erliquiose, o que demostram uma necessidade urgência na realização de estudos que pesquisem e divulguem os riscos de contaminação e risco a saúde pública a população humana bem como a população de felinos.

A região sudeste do país é a que mais publica sobre o tema $(n=31 ; 54 \%)$, sendo destaque o estado de São Paulo. Isso pode estar associado ao fato deste estar em região de Mata Atlântica, local onde a urbanização mais afetou o meio ambiente. A população vivendo concentrada faz com que os animais vivam em ambientes extremamente limitados e o gato foi o animal perfeito para tal situação. Em contrapartida, o abandono desses animais e a falta de cuidados, proporcionou a ocorrência de gatos errantes e ferais em toda a região. Em seguida, região Sul $(\mathrm{n}=11 ; 18 \%)$, Nordeste $(\mathrm{n}=9 ; 17 \%)$, Norte $(\mathrm{n}=4 ; 6 \%)$ e Centro-Oeste $(\mathrm{n}=3 ; 5 \%)$ (Figura 3$)$.

A análise da distribuição das publicações nos estados brasileiros revelou que os trabalhos publicados foram executados em São Paulo $(\mathrm{n}=21 ; 36 \%)$, seguidos de Pernambuco $(\mathrm{n}=8 ; 14 \%)$, Rio Grande do Sul $(n=8 ; 14 \%)$, Rio de Janeiro $(n=6 ; 10 \%)$, Minas Gerais $(n=4 ; 7 \%)$, Santa Catarina $(n=2 ; 3 \%)$, seguidos por Paraná, Pará, Amazonas, Rio Grande do Norte, Tocantins, Ceará, Mato Grosso do Sul, Distrito Federal e Goiás, ambos com $(\mathrm{n}=1 ; 1,7 \%)$. 
De acordo com os mecanismos de busca, os trabalhos com destaque para "Gatos Ferais" foram publicados no Brasil a partir do ano de 2002 (Figura 5). A partir daí, com exceção do ano de 2003, em todos os demais anos pelo menos um trabalho foi publicado. Destaque para os anos de 2015 e 2016, apresentando respectivamente 9 e 7 trabalhos no cenário nacional. Em 2015, com mais trabalhos publicados, existe uma variedade de estados publicando nesse mesmo ano, como São Paulo, Rio de Janeiro, Pará e Goiás.

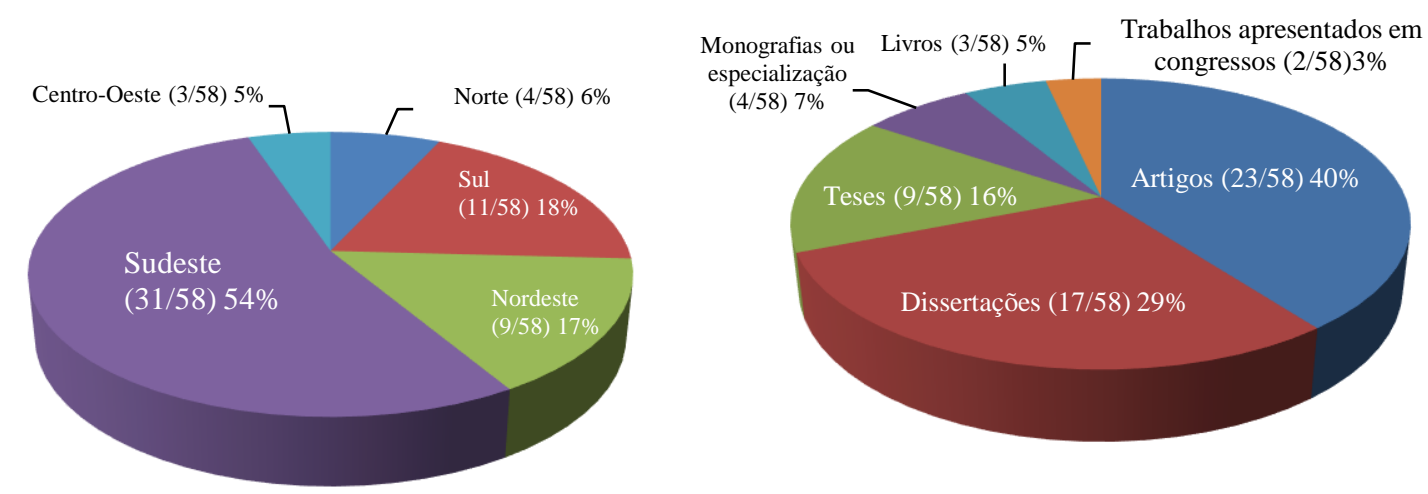

Figura 3. Distribuição dos estudos científicos publicados Figura 4. Distribuição dos estudos científicos publicados sobre o sobre o tema Gatos Ferais, no Brasil em relação às regiões brasileiras, no período de 2002 e 2019. tema Gatos Ferais, no Brasil em relação às vias de apresentação no período de 2002 a 2019

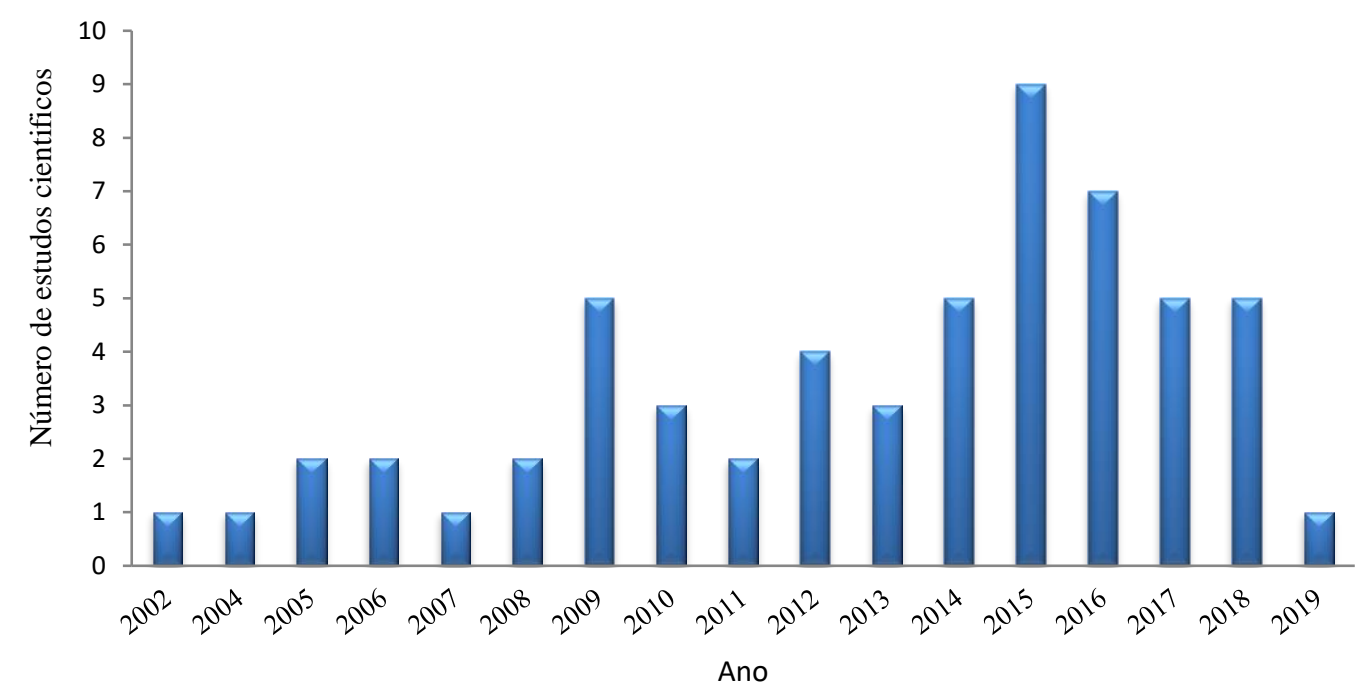

Figura 5. Número total de estudos científicos publicados sobre o tema Gatos Ferais, no Brasil em relação ao ano de publicação

Em relação a via de publicação, 23 (39,6\%) são artigos publicados em revistas científicas, $17(29,4 \%)$ são temas de dissertações, $9(15,5 \%)$ de teses, $4(6,9 \%)$ de monografias (de graduação ou especialização), $3(5,2 \%)$ livros e somente $2(3,4 \%)$ trabalhos apresentados em Congresso/Seminário (Figura 4 e Quadro 1).

O gato doméstico está difundido no mundo todo e os membros dessa família são abundantes caçadores. São animais extremamente adaptáveis e suscetíveis a adaptações, sendo variáveis em seu habitat, passando muito tempo caçando ou raramente deixando as residências de seus donos (Campos, 2004). Um animal que em sua evolução, mesmo sendo um animal de companhia, manteve características de semi ou total independência em relação ao homem pode ser classificado em três categorias, de acordo com o local e a forma como vivem: gatos domésticos (estão sob atenção de um proprietário), errantes (perambulam em torno de cidades ou propriedades rurais, não possuem proprietários, mas podem depender de recursos fornecidos por seres humanos) e ferais (vivem em estado selvagem, por meio da caça ou procurando restos de alimentos) (Ferreira et al., 2012; Vilela \& Lamim-Guedes, 2014). 
Quadro 1. Relação dos estudos científicos realizados no Brasil, sobre o tema Gatos ferais, contendo o ano de publicação, os autores, o título e a via de publicação.

\begin{tabular}{|c|c|c|c|}
\hline Ano & Autor & Título do trabalho & Via de publicação \\
\hline 2002 & Oliveira APF & $\begin{array}{l}\text { Comportamento social de machos e fêmeas castrados do gato } \\
\text { doméstico (Felis catus L.) em confinamento }\end{array}$ & Dissertação - USP \\
\hline 2004 & Campos CB & $\begin{array}{l}\text { Impacto de cães (Canis familiaris) e gatos (Felis catus) errantes } \\
\text { sobre a fauna silvestre em ambiente peri-urbano }\end{array}$ & Dissertação USP \\
\hline 2005 & Curi NHA & $\begin{array}{l}\text { Avaliação do estado de saúde e do risco de transmissão de doenças } \\
\text { entre canídeos (Mammalia, carnivora) silvestres e domésticos na } \\
\text { região da Serra do Cipó, Minas Gerais: implicações para a } \\
\text { conservação }\end{array}$ & $\begin{array}{l}\text { Dissertação - PUC Minas } \\
\text { Gerais }\end{array}$ \\
\hline 2005 & Carlos et al. & $\begin{array}{l}\text { Descrição comparativa do comportamento de gatos de estimação, } \\
\text { gatos semi-ferais e gatos castrados }\end{array}$ & $\begin{array}{l}\text { Resumo científico } \\
\text { apresentado em } \\
\text { Congresso - EAE }\end{array}$ \\
\hline 2006 & Galetti \& Sazima & $\begin{array}{l}\text { Impacto de cães ferais em um fragmento urbano de Floresta Atlântica } \\
\text { no sudeste do Brasil }\end{array}$ & $\begin{array}{l}\text { Revista - Natureza \& } \\
\text { Conservação }\end{array}$ \\
\hline 2006 & Neto GG & $\begin{array}{l}\text { Frequência de anticorpos contra Leptospira spp. em felídeos } \\
\text { neotropicais em cativeiro no Brasil }\end{array}$ & Dissertação - UNESP \\
\hline 2007 & Souza JOT & $\begin{array}{l}\text { Comportamento de gatos domésticos (Felis catus Linnaeus, 1758): } \\
\text { orquiectomia e desenvolvimento }\end{array}$ & Dissertação UFJF \\
\hline 2008 & Santos APS & $\begin{array}{l}\text { Infecção por hemoplasma em felinos domésticos na região de Porto } \\
\text { Alegre, RS, Brasil }\end{array}$ & Tese - UFRGS \\
\hline 2008 & Mariscal et al. & Alterações na comunidade causada por espécies invasoras & $\begin{array}{l}\text { Trabalho apresentado em } \\
\text { seminário - } \\
\text { UNICAMP/PG ecologia }\end{array}$ \\
\hline 2009 & Roda \& Dechoum & Contextualização Sobre Espécies Exóticas Invasoras & Livro \\
\hline 2009 & Fernandes GF & $\begin{array}{l}\text { Características fenotípicas, genotípicas, soroepidemiológicas, } \\
\text { antigênicas, imunoquímicas e de virulência de isolados brasileiros de } \\
\text { sporothrix schenckii. }\end{array}$ & Tese - UNIFESP \\
\hline 2009 & Metzger B & $\begin{array}{l}\text { Diagnóstico de hemoparasitas em felídeos neotropicais provenientes } \\
\text { de vida livre no Brasil }\end{array}$ & Dissertação - Unesp \\
\hline 2009 & Meireles GS & $\begin{array}{l}\text { Utilização da técnica de Western Blotting para diagnóstico da } \\
\text { infecção por Cystoisospora felis (Wenyon,1923) Frenkel, } 1977 \\
\text { (Apicomplexa: Cystoisosporinae) em coelhos (Oryctolagus } \\
\text { cuniculus) }\end{array}$ & Dissertação - UFRRJ \\
\hline 2009 & Pinto et al. & $\begin{array}{l}\text { Soroepidemiologia de Toxoplasma gondii em gatos domiciliados } \\
\text { atendidos em clínicas particulares de Porto Alegre, RS, Brasil }\end{array}$ & Revista Ciência Rural \\
\hline 2010 & Furtado MM & $\begin{array}{l}\text { Estudo epidemiológico de patógenos circulantes nas populações de } \\
\text { onça-pintada e animais domésticos em áreas preservadas de três } \\
\text { biomas brasileiros: Cerrado, Pantanal e Amazônia }\end{array}$ & Tese - USP \\
\hline 2010 & Genaro $\mathrm{G}$ & $\begin{array}{l}\text { Gato doméstico: futuro desafio para controle da raiva em áreas } \\
\text { urbanas? }\end{array}$ & $\begin{array}{l}\text { Revista-Pesquisa } \\
\text { Veterinária Brasileira }\end{array}$ \\
\hline 2010 & Dantas LMS & $\begin{array}{l}\text { Comportamento social de gatos domésticos e sua relação com a } \\
\text { clínica médica veterinária e o bem-estar animal }\end{array}$ & Tese - UFF \\
\hline 2011 & Jorge et al. & $\begin{array}{l}\text { Risk factors for feline leukemia virus (FeLV) infection in cats in São } \\
\text { Paulo, Brazil }\end{array}$ & $\begin{array}{l}\text { Brazilian Journal of } \\
\text { Veterinary Research and } \\
\text { Animal Science }\end{array}$ \\
\hline 2011 & Leão et al. & $\begin{array}{l}\text { Espécies exóticas invasoras no nordeste do Brasil: contextualização, } \\
\text { manejo e políticas públicas }\end{array}$ & Livro \\
\hline 2012 & Printes RC & $\begin{array}{l}\text { Gestão ambiental e negociação de conflitos em unidades de } \\
\text { conservação do nordeste do Rio Grande do Sul }\end{array}$ & Livro \\
\hline 2012 & Cunha RCSC & $\begin{array}{l}\text { Ocorrência de anticorpos anti-Leptospira spp., anti-Toxoplasma } \\
\text { gondii e anti- Neospora caninum em carnívoros selvagens e } \\
\text { domésticos de Unidades de Conservação de Pernambuco }\end{array}$ & Dissertação - UFRP \\
\hline 2012 & Damasceno J & $\begin{array}{l}\text { Enriquecimento ambiental alimentar para gatos domésticos (Felis } \\
\text { silvestris catus): aplicações para o bem-estar felino }\end{array}$ & Dissertação - USP \\
\hline 2012 & Ferreira et al. & Gatos: Vilões ou vítimas & $\begin{array}{l}\text { Revista Expedição de } \\
\text { Campo }\end{array}$ \\
\hline 2013 & Almeida \&Jesus & $\begin{array}{l}\text { Predação do sabiá-gongá Saltator coerulescens (Thraupidae) e do } \\
\text { pardal Passer domesticus (Passeridae) por gato doméstico Felis catus } \\
\text { (Carnivora: Felidae) }\end{array}$ & $\begin{array}{l}\text { Revista Atualidades } \\
\text { Ornitológicas }\end{array}$ \\
\hline
\end{tabular}




\begin{tabular}{|c|c|c|c|}
\hline Ano & Autor & Título do trabalho & Via de publicação \\
\hline 2013 & Lopes LR & Manejo de doenças infecciosas em gatos de abrigos & Monografia - UFRGS \\
\hline 2013 & Coelho EM & $\begin{array}{l}\text { Aspectos clínico-patológicos da infecção pelo vírus da leucemia } \\
\text { felina }\end{array}$ & Monografia - UFRGS \\
\hline 2014 & Matesco VC & Infecção pelo vírus da leucemia felina: revisão e relato de caso & Monografia - UFRGS \\
\hline 2014 & Montaño PY & $\begin{array}{l}\text { Ocorrência de coinfecções em gatos domésticos anêmicos e não } \\
\text { anêmicos }\end{array}$ & Dissertação - UFPR \\
\hline 2014 & $\begin{array}{l}\text { Vilela \& Lamim- } \\
\text { Guedes }\end{array}$ & Cães domésticos em unidades de conservação: impactos e controle & $\begin{array}{l}\text { Revista - Holos } \\
\text { Environment }\end{array}$ \\
\hline 2014 & Souza, et al. & $\begin{array}{l}\text { Bartonelose: análise molecular e sorológica em gatos do Rio de } \\
\text { Janeiro, Brasil }\end{array}$ & $\begin{array}{l}\text { Revista Brasileira de } \\
\text { Ciência Veterinária }\end{array}$ \\
\hline 2014 & Favretto MA & Seleção natural e seleção sexual em aves & $\begin{array}{l}\text { Revista Atualidades } \\
\text { Ornitológicas }\end{array}$ \\
\hline 2015 & Ramos IFB & $\begin{array}{l}\text { Manejo populacional de gatos (Felis silvestris catus): uma } \\
\text { abordagem comportamental }\end{array}$ & Dissertação - USP \\
\hline 2015 & Paixão RL & $\begin{array}{l}\text { Conexões entre o comportamento do gato doméstico e casos de } \\
\text { maus-tratos, abandono e não adoção }\end{array}$ & $\begin{array}{l}\text { Revista Brasileira de } \\
\text { Direito Animal }\end{array}$ \\
\hline 2015 & Nunes JOR & $\begin{array}{l}\text { Entendendo o comportamento canino: estudo das causas de agressão } \\
\text { e sua influência na profilaxia da raiva humana }\end{array}$ & Tese - UNESP \\
\hline 2015 & Silveira FLA & $\begin{array}{l}\text { De um prosaico coexistir interespecífico aos dilemas do biopoder: as } \\
\text { interações humanas e não humanas no mundo urbano contemporâneo } \\
\text { amazônico }\end{array}$ & $\begin{array}{l}\text { ILHA - Revista de } \\
\text { Antropologia }\end{array}$ \\
\hline 2015 & Islas CA & $\begin{array}{l}\text { Conhecimento ecológico caiçara sobre animais silvestres como } \\
\text { aporte para um manejo de base ecossistêmica }\end{array}$ & Dissertação - UNICAMP \\
\hline 2015 & Costa RCB & $\begin{array}{l}\text { Estudo epidemiológico da coinfecção por toxoplasma gondii e pelo } \\
\text { vírus da imunodeficiência felina em gatos domésticos (felis catus) em } \\
\text { Goiânia, Goiás }\end{array}$ & Dissertação - UFG \\
\hline 2015 & Wanderley MCP & $\begin{array}{l}\text { Ocorrência de Escherichia coli resistente a antimicrobianos em } \\
\text { diferentes sítios corporais em uma população diversa de gatos } \\
\text { saudáveis }\end{array}$ & Tese - UNESP \\
\hline 2015 & Gennari et al. & $\begin{array}{l}\text { Toxoplasma gondii antibodies in wild rodents and marsupials from } \\
\text { the Atlantic Forest, state of São Paulo, Brazil }\end{array}$ & $\begin{array}{l}\text { Revista Brasileira de } \\
\text { Parasitologia Veterinária }\end{array}$ \\
\hline 2015 & Guimarães TCS & $\begin{array}{l}\text { Espécies exóticas invasoras da fauna em unidades de conservação } \\
\text { federais no Brasil: sistematização do conhecimento e implicações } \\
\text { para o manejo }\end{array}$ & Dissertação - UnB \\
\hline 2016 & Caldas SR. & Impactos ambientais sobre a floresta da UFAM & Dissertação - UFAM \\
\hline 2016 & Ferreira GA & $\begin{array}{l}\text { Gatos domésticos em ambiente insular de Mata Atlântica: potenciais } \\
\text { impactos sobre mamíferos silvestres e a castração como estratégia } \\
\text { para conservação }\end{array}$ & Tese - UFJF \\
\hline 2016 & Santiago R & $\begin{array}{l}\text { Levantamento da avifauna da Estação Experimental da Syngenta em } \\
\text { Holambra }\end{array}$ & $\begin{array}{l}\text { Revista Intertox de } \\
\text { Toxicologia Risco } \\
\text { Ambiental e Sociedade }\end{array}$ \\
\hline 2016 & Magalhães FJR & $\begin{array}{l}\text { Infecção por Toxoplasma gondii em animais na Ilha de Fernando de } \\
\text { Noronha, Brasil: prevalência, distribuição espacial e fatores de risco }\end{array}$ & Tese - UFRPE \\
\hline 2016 & $\begin{array}{l}\text { Bandeira de Melo } \\
\text { RP }\end{array}$ & $\begin{array}{l}\text { Isolamento e caracterização genética de Toxoplasma gondii de gatos } \\
\text { ferais no Arquipélago de Fernando de Noronha, Pernambuco, Brasil }\end{array}$ & Dissertação - UFRPE \\
\hline 2016 & Santiago R & $\begin{array}{l}\text { Levantamento da mastofauna de médio e grande porte da Estação } \\
\text { Experimental Syngenta de Holambra, SP }\end{array}$ & $\begin{array}{l}\text { Revista Intertox de } \\
\text { Toxicologia Risco } \\
\text { Ambiental e Sociedade }\end{array}$ \\
\hline 2016 & Xavier MS & $\begin{array}{l}\text { Mamíferos terrestres de médio e grande porte do Parque Nacional da } \\
\text { Restinga de Jurubatiba: riqueza de espécies e vulnerabilidade local }\end{array}$ & Dissertação - UFRJ \\
\hline 2017 & Kerber SS & $\begin{array}{l}\text { Predação por gatos domésticos (Felis catus) em ambiente urbano, } \\
\text { Florianópolis, Santa Catarina }\end{array}$ & Monografia - UFSC \\
\hline 2017 & Lima et al. & $\begin{array}{l}\text { Parasitos gastrointestinais em gatos ferais e roedores do Arquipélago } \\
\text { de Fernando de Noronha, Brasil }\end{array}$ & $\begin{array}{l}\text { Revista Brasileira de } \\
\text { Parasitologia Veterinária }\end{array}$ \\
\hline 2017 & Paz et al. & Fatores relacionados a problemas de comportamento em gatos & $\begin{array}{l}\text { Revista Pesquisa } \\
\text { Veterinária Brasileira }\end{array}$ \\
\hline 2017 & Pereira et al. & $\begin{array}{l}\text { Gastrointestinal parasites in stray and shelter cats in the municipality } \\
\text { of Rio de Janeiro, Brazil }\end{array}$ & $\begin{array}{l}\text { Revista Brasileira de } \\
\text { Parasitologia Veterinária }\end{array}$ \\
\hline
\end{tabular}




\begin{tabular}{|l|l|l|l|}
\hline Ano & \multicolumn{1}{|c|}{ Autor } & Título do trabalho & \multicolumn{1}{|c|}{ Via de publicação } \\
\hline 2017 & Machado et al. & $\begin{array}{l}\text { Interação entre gatos domésticos (Felis silvestris catus Linnaeus, } \\
\text { 1758) cativos e seres humanos }\end{array}$ & $\begin{array}{l}\text { Revista } \\
\text { Zoociências }\end{array}$ \\
\hline 2018 & Braga et al. & $\begin{array}{l}\text { Avaliação clínica e laboratorial de gatos domésticos colonizados no } \\
\text { Campus do Pici da UFC: protocolo prático e de baixo custo para } \\
\text { monitoramento sanitário }\end{array}$ & $\begin{array}{l}\text { Revista Brasileira de } \\
\text { Higiene e Sanidade } \\
\text { Animal }\end{array}$ \\
\hline 2018 & Lima VFS & $\begin{array}{l}\text { Agentes parasitários em animais silvestres, sinantrópicos e } \\
\text { domésticos: aspectos clínicos, epidemiológicos e de saúde pública }\end{array}$ & Tese - UFRPE \\
\hline 2018 & Ribeiro et al. & $\begin{array}{l}\text { Infecção por Leptospira } \text { spp. Em Gatos (Felis silvestris catus) - uma } \\
\text { Revisão }\end{array}$ & $\begin{array}{l}\text { Revista Brasileira de } \\
\text { Higiene e Sanidade } \\
\text { Animal }\end{array}$ \\
\hline 2018 & Trindade et al. & $\begin{array}{l}\text { Dioctophyme renale (Nematoda: Dioctophymatidae) in Leopardus } \\
\text { geoffroyi (Carnivora: Felidae) in the Neotropical region }\end{array}$ & $\begin{array}{l}\text { Revista Brasileira de } \\
\text { Parasitologia Veterinária }\end{array}$ \\
\hline 2018 & Morais et al. & $\begin{array}{l}\text { Geo-Epidemiological Study of Leptospira } \text { spp. Infection in Cattle, }, \\
\text { Feral Cats and Rodents of the Fernando de Noronha Island, Brazil }\end{array}$ & $\begin{array}{l}\text { Revista Acta Scientiae } \\
\text { Veterinariae }\end{array}$ \\
\hline 2019 & Lopes et al. & $\begin{array}{l}\text { Occurrence of } \text { Ehrlichia canis and Hepatozoon canis and probable } \\
\text { exposure to Rickettsia amblyommatis in dogs and cats in Natal, RN }\end{array}$ & $\begin{array}{l}\text { Revista Brasileira de } \\
\text { Parasitologia Veterinária }\end{array}$ \\
\hline
\end{tabular}

Gatos ferais se aproximaram dos ambientes humanos pela disponibilidade de alimento e abrigo, sendo tolerados pelas pessoas. $\mathrm{O}$ abandono, ninhadas indesejadas e a má compreensão do comportamento desses animais, faz crescer o número deles no meio urbano. A presença desses animais em ambientes urbanos ou silvestres é preocupante, já que são mesopredadores, principalmente as aves, podendo levar ao declínio e a extinção das espécies presas. A introdução de organismos exóticos vem causando um importante e maléfico impacto nas espécies nativas, principalmente em ilhas ou populações isoladas. Além disso, são potenciais transmissores de doenças contagiosas, como toxoplasmose, raiva e leptospirose. É verídico que a caça clandestina e o desmatamento possuem efeito importante na redução da população de fauna, mas o impacto dos animais ferais ainda é menosprezado. (Galetti \& Sazima, 2006; Padilha, 2009; Paixão \& Machado, 2015).

Por muito tempo, equivocadamente, considerou-se que gatos eram animais solitários. A organização social é estruturada numa forma hierárquica linear de dominância, a qual é formada por machos dominantes (reprodutores) e machos subordinados. A determinação espacial de fêmeas se dá pela abundância de alimentos, enquanto a do macho é determinada pela distribuição de fêmeas receptivas pelo menos no período de acasalamento. O território de machos é bem maior que o das fêmeas, estes incluem locais de descanso e alimentação (Galetti \& Sazima, 2006). Quando animais ferais estão presentes numa região é um indicativo significante na emergência de doenças na vida silvestre. Entrando em contato tanto com animais silvestres, quanto com animais domésticos, podem se tornar "conduítes" para a troca de patógenos entre populações isoladas, resultando em uma ameaça para, além de animais silvestres, animais domésticos e seres humanos (Curi, 2005).

No Arquipélago de Fernando de Noronha, Pernambuco, Brasil, os gatos ferais são mais suscetíveis à infecção por Toxoplasma gondii, devido ao hábito da caça de roedores e pequenos pássaros, e assim, ingerem facilmente os cistos do protozoário presente nos tecidos destas presas. E como estes felinos são importantes na cadeia epidemiológica da Toxoplasmose, a contaminação ambiental por oocistos leva a um risco para a saúde pública e animal. (Melo, 2016)

\section{Considerações finais}

Na literatura há uma escassez de trabalhos no Brasil sobre gatos ferais, seus impactos causados aos demais animais, as enfermidades que podem ser transmitidas e seu comportamento. A região que mais publica no Brasil é a sudeste, local onde a população vive de forma concentrada, e os gatos, animais extremamente adaptáveis a ambientes adversos se estabeleceram e por uma série de fatores, como a interpretação incorreta de seu comportamento, são abandonados e a partir daí podem se estabelecer de modo independente, feral no ambiente.

Os gatos ferais são passíveis de transmitir doenças não somente à fauna silvestre brasileira, mas aos demais animais domésticos e humanos. Dentre os estudos científicos sobre esses animais no Brasil, a categoria Doenças/Zoonoses foi a que mais trouxe resultados, sendo estes estudos considerados 
recentes. Dentre as zoonoses mais estudadas, a que mais se destacou foi a Toxoplasmose. Mesmo assim, são poucos os estudos que tratam desta problemática, bem como de alternativas de prevenção.

\section{Referências bibliográficas}

Campos, C. B. de. (2004). Impacto de cães (Canis familiaris) e gatos (Felis catus) errantes sobre a fauna silvestre em ambiente peri-urbano. Universidade de São Paulo.

Curi NHA. Avaliação do estado de saúde e do risco de transmissão de doenças entre canídeos (Mammalia, Carnivora) silvestres e domésticos na região da serra do cipó, minas gerais: implicações para a conservação. 100p. [Dissertação] Belo Horizonte: Pontifícia Universidade Católica de Minas Gerais; 2005.

Ferreira, G. A., Nakano-Oliveira, E. \& Genaro, G. (2012). Gatos: Vilões ou vítimas. Revista Expedição de Campo, 3, 22-26.

Galetti, M., \& Sazima, I. (2006). Impacto de cães ferais em um fragmento urbano de Floresta Atlântica no sudeste do Brasil. Natureza \& Conservação, 4(1), 58-63.

Kerber, S. S. (2017). Predação por gatos domésticos (Felis catus) em ambiente urbano, Florianópolis, Santa Catarina. Florianópolis, SC.

Melo RPB. Isolamento e caracterização genética de Toxoplasma gondii de gatos ferais no Arquipélago de Fernando de Noronha, Pernambuco, Brasil. 54p. [tese] Recife: Universidade Federal Rural de Pernambuco; 2016.

Padilha, J. C. (2009). Avaliação da predação de ovos em ninhos artificiais por callithrix spp. em Paraty, RJ. Revista Controle Biológico, 1, 1-6.

Paixão, R. L., \& Machado, J. C. (2015). Connections between domestic cat behavior and abuse cases, abandonment and not adopting. Revista Brasileira de Direito Animal, 10(20), 1-32.

Vilela, A. L. O., \& Lamim-Guedes, V. (2014). Cães domésticos em unidades de conservação: impactos e controle. Holos Environment, 14(2), 198-210.

Recebido: 15 de janeiro, 2020.

Aprovado: 11 de fevereiro, 2020.

Disponível online: 17 de junho, 2020.

Licenciamento: Este artigo é publicado na modalidade Acesso Aberto sob a licença Creative Commons Atribuição 4.0 (CC-BY 4.0), a qual permite uso irrestrito, distribuição, reprodução em qualquer meio, desde que o autor e a fonte sejam devidamente creditados. 